\title{
The Direction of Causality Between Supply Chain Excellence and Firm Performance
}

Min Shi, Department of Management, California State University, Los Angeles, USA

\begin{abstract}
A widely-accepted measure of supply chain excellence is the Supply Chain Top 25 List published annually by Gartner Research. It evaluates firms from five quality dimensions: return on assets, inventory turns, revenue growth, peer evaluation, and Gartner opinion. However, subjective voting by industrial experts and Gartner consultants are likely to be influenced by financial market variables, such as a firm's market value, alpha, beta, and market return. This article investigates whether the Gartner list is a true reflection of a firm's SCM excellence and how market variables affect the Gartner list, especially its subjective quality dimensions. Correlation and regression analysis show that the Gartner list is largely affected by a firm's market value and alpha, but is not associated with the firm's beta and market return. Moreover, the Gartner list is influenced by a firm's prior market information, but is not capable to predict its future performance.
\end{abstract}

\section{KEYWORDS}

Firm Performance, Gartner List, Market Variables, Subjective Evaluations, Supply Chain Excellence

\section{INTRODUCTION}

Supply chain management (SCM) has attracted substantial attention across various industries during the past decades. According to Shi \& Yu (2013), SCM was viewed by many corporate executives as a strategically important enabler of business with significant impacts on both accounting- and market-based performance. A high reputation in SCM not only stimulates investor confidence, but also facilitates firms to get access to lower costs of capital. Several studies have shown that a firm's excellent SCM is closely related to its financial success by influencing three of its major drivers: revenue, operating costs and working capital (Christopher \& Ryals, 1999; Ellinger et al., 2011).

A widely-accepted SCM excellence survey is the Supply Chain Top 25 List ("the Gartner list"), which is published annually by Gartner Research (formally AMR Research) to promote SCM awareness and its impacts on business. Primarily derived from a master list of Fortune Global 500, the Gartner list is restricted to the manufacturing and retailing sectors and excludes certain industries, such as financial services, insurance, energy, transportation, construction, and communications. Specifically, the overall composite score is calculated based on five quality dimensions: industrial peer evaluation, Gartner expert opinion, 3-year weighted return on assets (ROA), inventory turns, and 3-year weighted revenue growth. The weights used for each dimension are slightly different year by year. For example, 
the weights used in year 2011 are $25 \%, 25 \%, 25 \%, 15 \%$, and $10 \%$, respectively. Starting from year 2016, a corporate social responsibility (CSR) score was added as the sixth dimension, thus changing the weights to $25 \%, 25 \%, 20 \%, 10 \%, 10 \%$, and $10 \%$, respectively. All the scores are then normalized onto a 10-point scale and aggregated into one SCM composite score. As the first and only publicly available reputation index dedicated to evaluating SCM excellence, the Gartner list is widely adopted in recent empirical SCM research (Ellinger et al., 2011, 2012; Swink et al., 2010).

In strategic management, it is well known that management reputation indexes, such as Fortune's "100 most admired corporation" and "100 best companies to work for in America," are strongly associated with financial performance (Fulmer et al., 2003; Flanagan, et al., 2011; Brown \& Perry, 1994). Therefore, there may also exist a "performance halo" in the Gartner list, which blurs the distinctions among certain quality dimensions due to strong overall impressions. In other words, is the composite score in the Gartner list a good measure of SCM excellence? Does SCM excellence lead to strong financial outcomes, or vice versa?

This paper aims to address these research questions by closely examining the Gartner list under the framework in strategic management. More specifically, it makes contributions to the literature in three perspectives. First, it analyzes the correlations between quality dimensions of the Gartner list so that researchers can better understand the relationship between subjective and objective measures in the Gartner list. Second, by following the research stream of McGuire, Schneeweis, \& Branch (1990) and Brown \& Perry (1994), it extends the research scope of SCM excellence by investigating the impacts of market variables on the composite scores and subjective evaluations in the Gartner list. Last, but not least, this study examines whether the Gartner list is a good indicator of a firm's future market performance and risk exposure. The results in this perspective can help practitioners better understand strategic values of SCM excellence.

The reminder of this paper is organized as follows. The next section reviews relevant literature in corporate reputation and supply chain management. The third section lays out the theoretical background and proposes several research hypotheses. Extensive correlation and regression analyses are conducted in the following section and the results are also discussed. In the last section, we conclude the paper and point out future research directions.

\section{LITERATURE REVIEW}

There have been extensive interests in literature to examine the relationship between firm reputation and financial performance. Most of studies focus on its existence and mechanism, which disclose how firm reputation makes contributions to financial performance, if any. Although a general wisdom indicates that firm reputation is an integrated part of intangible assets to gain competitive advantages, its contribution and functionality to financial performance evoked intense debates and divergent views within the SCM community.

Some studies have successfully established positive relationships between firm reputation and financial performance based on a resource-based view (RBV), which indicates that a firm with unique and inimitable resources may possess competitive advantage and achieve superior financial performance. Based on Fortune Magazine's American's Most Admired Corporations data from 1984 to 1998 , Robert \& Dowling (2002) find that firms with relatively good reputation are able to persistently maintain superior financial outcomes. Using reputational data from a large-scale survey of 30 largest German firms, Eberl \& Schwaiger (2005) investigate the effect of corporate reputation on future financial performance. Specifically, they decompose the concept of reputation into cognitive and affective factors. After controlling for past performance, they find that these two reputational dimensions affect the financial performance in different ways. While the cognitive component, similar to the one used in Robert \& Dowling (2002), makes positive contribution to future financial performance, the affective component has a negative impact. 
However, not all the studies successfully recognize the relationship between firm reputation and financial outcomes. Based on Australian reputation index known as RepuTex, Inglis et al. (2006) find no causal relationship between firm reputation and financial performance in either direction. However, they point out that, rather than challenging the common wisdom regarding the financial impacts of corporate reputation, their study actually casts doubts on the validity of RepuTex and calls for more reliable measures of corporate reputation. In another study, Rose \& Thomsen (2004) use reputational data from a Danish business journal to investigate the causal relationship between firm reputation and financial performance, particularly the market-to-book ratio. They find that firm reputation does not improve financial performance whereas past financial performance has a positive impact on firm reputation.

In SCM area, previous empirical studies tend to focus on relationship between certain aspects of SCM excellence and firm performance. For example, Chen et al. (2004) apply structural equation model to identify positive links between strategic purchasing, supply management, customer responsiveness, and financial performance. By examining inventory data of large U.S. manufacturing companies between 1981 and 2000, Chen et al. (2005) find that long-term stock returns are positively associated with inventory levels, but lowest inventory level does not necessarily bring in significant returns. Hendricks and Singhal developed a series of empirical studies to examine the financial impacts of supply chain disruptions, such as supply chain glitch (Hendricks \& Singhal, 2003, 2005), product introduction delay (Hendricks \& Singhal, 2008), and excess inventory (Hendricks \& Singhal, 2009). In general, they find statistically significant negative market reactions to the announcements of supply chain disruptions. In addition, Hendricks \& Singhal (2014) show that long-term equity volatility is significantly related to all three types of SC disruptions.

Therefore, several studies adopt the Gartner list as a "unified proxy" of SCM competency (Johnson \& Templar, 2011) to examine its relationship with firms' financial performance. From a practitioner's perspective, Swink et al. (2010) combine the Gartner list and other data sources to identify leading SCM firms in various industries and investigate their financial performance. They find that the leading SCM firms significantly outperform comparable companies in almost all operational and financial metrics. The average monthly stock returns of the leading SCM firms are also significantly higher than their close competitors. They suggest that some performance metrics, such as ROA, SG\&A/sales, and working capital/sales, be most powerful indicators to differentiate the leading SCM firms from their rivals. Ellinger et al. (2011) use subjective components (peel evaluations and Gartner opinions) in the 2007-2009 Gartner lists to examine how SCM reputation is related to the firm-level financial health, which is measured by Altman's (1968) Z-score statistic. The empirical results demonstrate that the top SCM firms have significantly higher Altman's Z-score than close competitors and industry averages. Using similar datasets from the 2007-2010 Gartner lists, Ellinger et al. (2012) identify positive relationship between top SCM firms and customer satisfaction rates, which are measured by American Customer Satisfaction Index (ACSI). Meanwhile, they find that top SCM firms exhibit higher level of shareholder value than their respective competitors.

It is worth noting that there are several limitations in the current literature regarding the relationship between SCM excellence and financial performance. First, current studies only use limited data from the Gartner list. All the new data in the Gartner list after 2010 is never used in the study. In addition, some studies (Ellinger et al. 2011, 2012) only use subjective dimensions from the Gartner list to avoid confounding effects of financial information. As a result, a lot of meaningful information in the Gartner list has been lost. Second, the measurements used in current studies may not appropriate for fully capturing the influences of SCM reputation. For example, as a comprehensive measure of financial health, Z-score is widely employed to predict bankruptcy likelihood, rather than intangible financial benefits and its overall effects on financial markets. Third, by comparing the past performance of SCM leader firms to that of competitor firms and industry averages, it fails to provide forward-looking indication on the impacts of SCM reputation in financial markets. 
In a similar framework as our study, McGuire et al. (1990) examine data on perceptions of firm quality from Fortune magazine's annual survey on corporate reputation and found that they are influenced by their financial performance and risk measures. Moreover, perceptions of firm quality are more closely related to prior financial performance, but provide little information to indicate future performance. However, two distinct differences exist between McGuire et al. (1990) and the current study. First, Fortune magazine's corporate reputation data is constructed mainly by subjective evaluations on various firm quality dimensions from thousands of corporate executives and analysts. As a result, the reputation measures are heavily influenced by previous financial outcomes and Brown \& Perry (1994) have to propose a method to remove so-called "halo effects" before they can be used in other research. The Gartner list, on the other hand, is more balanced by comprising of two subjective and three objective measures, thus potentially reducing the "halo effects" as shown in the following correlation analysis. Second, both McGuire et al. (1990) and Brown \& Perry (1994) focus on firms' accounting measures and market risks, but fail to recognize the importance of other market variables, such as market returns, market capitalization, and even media exposure. By including these variables in the study, this paper further investigates the relationship between corporate reputation and financial performance.

\section{Research Hypothesis}

Since the evaluators of the Gartner list are likely influenced by financial market information, the composite scores in the Gartner list may not be a true reflection of SCM excellence. In order to address this concern, our research hypotheses are designed as follows. The first hypothesis is to examine whether the composite score of the Gartner list is highly correlated with its five quality measures. As a matter of fact, three of them, ROA, inventory turns, and revenue growth, are commonly used to measure corporate reputation in the literature (Brown \& Perry, 1994). As McGuire et al. (1990) point out, revenue growth and operating income are seldom significantly associated with reported qualitative performance indexes. Therefore, our first hypothesis states:

H1: In the Gartner list, correlations between the composite score and five quality dimensions are moderate to low.

On the other hand, it is well known that any subjective rating is inevitably subject to external influences. In this sense, market-based financial variables, including both performance and risk measures, may play a more important role than accounting measures for determining firm qualities. In addition, market variables are supposed to be more reliable and trustful than self-reported accounting measures in terms of managerial manipulations. The evaluators are likely to cast a favorable vote because of a firm's impressive market information, rather than its SCM excellence. Consequently, the voting results of the Gartner list are expected to be impacted by several market variables, such as market value, Alpha, Beta, and total stock return.

Market value can be found by multiplying the current stock price and the total number of shares outstanding. The larger a firm's market value, the more favorable press and analyst coverage it is likely to receive. Media and analyst coverage help to spread good words about its products and services to a wider audience, including SCM professionals and consultants. Therefore, market value is used as an approximation of media exposure in this study and is expected to have some positive effects on a firm's SCM reputation. Therefore, the second hypothesis is as follows:

H2: A firm's market value is positively associated with the SCM composite score and subjective evaluations. 
Alpha is a historical measure of a stock's return compared to risk-adjusted expected return in market. It can be used as an approximation of stock abnormal return under certain market conditions, or a variable for measuring relative strength of a firm's stock to its competitors. Similarly, total stock return is calculated as the price change in the prior year plus any dividends paid, divided by the original price of the stock. It is used as a variable to represent net gain of a firm's market performance. It is expected that higher return, no matter it is net gain or relative strength, will create momentum stocks and therefore is positively attributed to a firm's SCM reputation. Therefore, the next hypothesis is written as:

H3: A firm's Alpha value and total stock return are both positively associated with SCM composite score.

Equally important, whether SCM excellence provides any indication on superior market performance in the following year is of interests in many previous studies. Unfortunately, the conclusions are somewhat ambiguous and unconvincing in the literature. By constructing the next hypothesis, we aim to investigate whether a firm's inclusion of the Gartner list results in subsequent improved market performance and risk exposure. We expect that the evaluator tends to be only influenced by a firm's prior market performance, but shall not be able to predict any change in market performance (Rose \& Thomsen, 2004; Shi \& Yu, 2018). Therefore, the hypothesis is described as follows:

H4: The subjective measures and composite score of the Gartner list are more correlated with a firm's prior market performance than its subsequent performance.

Several risk factors, such as beta, total volatility, and system risk, are also included in the model to study stock volatility. Since a preliminary correlation analysis shows a high correlation between these risk factors (higher than 0.80), we only kept Beta in the model in order to avoid multicollinearity conundrum in regression analysis. By measuring how a stock moves versus a benchmark index, Beta is often used as an indicator of a firm's risk exposure - a higher Beta implies a riskier investment. Therefore, the last hypothesis we are going to examine is:

H5: A firm's Beta value is negatively associated with the SCM composite score.

\section{DATA ANALYSIS}

\section{Data}

The annual Gartner lists from 2007 to 2015 are collected from the Gartner website. Since Gartner has added CSR score as the sixth category since 2016, the most recent year data is not included in this section to keep analysis consistent. If a firm is voted to be on the Gartner list in a particular year, its three-year (preceding, current, and following) financial information and stock prices are retrieved from the COMPUSTAT and CRSP databases, respectively. It is worth noting that the complete market information of several frequent winners in the Gartner lists, such as Samsung and H\&M, is not available in the databases. As a result, $174 \mathrm{firm} / \mathrm{years}$ were included in the analytical process. The relationship between the Gartner quality dimensions and firms' market information are examined by correlation and regression analysis.

\section{Regression Analysis}

While the correlation analysis clearly demonstrates the relationships between any pair of variables, regression analysis is expected to provide more comprehensive understanding regarding the market 
variables and perception of supply chain excellence. In this section, three regression studies are conducted and their results are presented in three corresponding panels of Table 2.

\section{Correlation Analysis}

A correlation analysis not only indicates the relationship between each pair of variables, but also provides useful insights to the following regression analysis. The correlation analysis results are presented in Table 1, which includes four panels. The first panel examines the relationships between

Table 1. Correlation matrix of the Gartner list and market variables

\begin{tabular}{|c|c|c|c|c|c|c|c|c|c|c|c|c|}
\hline & ֻّँّ & 离 & $\underset{ఝ}{\simeq}$ & 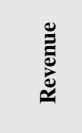 & $\begin{array}{l}\overrightarrow{0} \\
\vec{\Xi} \\
\vec{\Xi}\end{array}$ & :ँّ̆ & 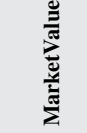 & 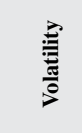 & 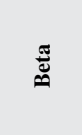 & $\frac{\pi}{\frac{\pi}{2}}$ & 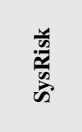 & 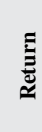 \\
\hline \multicolumn{13}{|l|}{$\begin{array}{l}\text { Panel 1: } \\
\text { GARTNER }\end{array}$} \\
\hline Peer & 1 & & & & & & & & & & & \\
\hline Gartner & $.634 * *$ & 1 & & & & & & & & & & \\
\hline ROA & $-.315^{* *}$ & $-.325 * *$ & 1 & & & & & & & & & \\
\hline Revenue & $.246 * *$ & $.153 *$ & .059 & 1 & & & & & & & & \\
\hline Inventory & $.206^{* *}$ & .097 & .063 & .102 & 1 & & & & & & & \\
\hline Score & $.742 * *$ & $.704^{* *}$ & .062 & $.453^{* *}$ & $.444 * *$ & 1 & & & & & & \\
\hline \multicolumn{13}{|l|}{$\begin{array}{l}\text { Panel 2: } \\
\text { Current Yr }\end{array}$} \\
\hline MarketValue & $.656^{* *}$ & $.432 * *$ & .132 & $.377 * *$ & $.187^{*}$ & $.647 * *$ & 1 & & & & & \\
\hline Volatility & -.040 & -.060 & -.029 & $.445^{* *}$ & -.032 & .065 & -.140 & 1 & & & & \\
\hline Beta & $-.217^{* *}$ & -.136 & .094 & $.301^{* *}$ & -.076 & -.039 & $-.217^{* *}$ & $.850^{* *}$ & 1 & & & \\
\hline Alpha & $.329 * *$ & .054 & .020 & $.525^{* *}$ & $.338 * *$ & $.409 * *$ & $.238 * *$ & $.176^{*}$ & -.039 & 1 & & \\
\hline SysRisk & .045 & -.010 & -.055 & $.505^{* *}$ & .003 & $.156^{*}$ & -.103 & $.945^{* *}$ & $.726 * *$ & $.260^{* * *}$ & 1 & \\
\hline Return & $.182^{*}$ & .000 & -.028 & $.190^{*}$ & .110 & $.216^{* *}$ & $.202 *$ & .132 & -.057 & $.375^{* *}$ & $.175^{*}$ & 1 \\
\hline \multicolumn{13}{|l|}{$\begin{array}{l}\text { Panel 3: } \\
\text { Previous Yr }\end{array}$} \\
\hline MarketValue & $.702 * *$ & $.458^{* *}$ & .087 & $.172 *$ & $.397 * *$ & $.667 * *$ & 1 & & & & & \\
\hline Volatility & -0.071 & -0.094 & -0.06 & -0.05 & $.409 * *$ & 0.036 & $-.171 *$ & 1 & & & & \\
\hline Beta & $-.265^{* *}$ & $-.173 *$ & 0.008 & -0.099 & $.300 * *$ & -0.095 & $-.264 * *$ & $.837 * *$ & 1 & & & \\
\hline Alpha & $.284 * *$ & 0.051 & 0.056 & $.267 * *$ & $.371 * *$ & $.363 * *$ & $.300 * *$ & 0.003 & $-.188 *$ & 1 & & \\
\hline SysRisk & 0.021 & -0.017 & -0.067 & -0.011 & $.466 * *$ & 0.141 & -0.104 & $.944 * *$ & $.692 * *$ & 0.111 & 1 & \\
\hline Return & $.176^{*}$ & 0.062 & -0.066 & 0.071 & 0.073 & 0.067 & 0.142 & 0.099 & -0.119 & $.289 * *$ & 0.124 & 1 \\
\hline \multicolumn{13}{|l|}{$\begin{array}{l}\text { Panel 4: } \\
\text { Next Yr }\end{array}$} \\
\hline MarketValue & $.607 * *$ & $.428 * *$ & 0.109 & 0.132 & $.288 * *$ & $.565^{* *}$ & 1 & & & & & \\
\hline Volatility & -0.075 & -0.054 & -0.001 & -0.027 & $.440 * *$ & 0.063 & $-.221 * *$ & 1 & & & & \\
\hline Beta & $-.178 *$ & -0.131 & 0.1 & -0.057 & $.281 * *$ & -0.028 & $-.248 * *$ & $.864 * *$ & 1 & & & \\
\hline Alpha & $.301 * *$ & 0.1 & -0.05 & $.346^{* *}$ & $.518^{* *}$ & $.406^{* *}$ & 0.06 & $.174 *$ & -0.059 & 1 & & \\
\hline SysRisk & 0.02 & -0.019 & -0.039 & 0.006 & $.507 * *$ & $.156^{*}$ & $-.205^{*}$ & $.945^{* *}$ & $.732 * *$ & $.279 * *$ & 1 & \\
\hline Return & 0.034 & 0.091 & 0.017 & 0.054 & 0.138 & 0.113 & 0.084 & $.185^{*}$ & -0.016 & $.264 * *$ & $.220 * *$ & 1 \\
\hline
\end{tabular}

Note: (1) **: Correlation is significant at the 0.01 level (2-tailed); (2) *: Correlation is significant at the 0.05 level (2-tailed) 
Table 2. Regression analysis between subjective measures and market variables

\begin{tabular}{|c|c|c|c|c|c|c|}
\hline & Intercept & MarketValue & Beta & Alpha & Return & Adjusted $\mathbf{R}^{2}$ \\
\hline \multicolumn{7}{|l|}{ Panel 1: Peer } \\
\hline \multirow{2}{*}{ Prior Year } & $660.838^{* *}$ & $0.004 * *$ & -181.144 & 9580.288 & 181.869 & 0.523 \\
\hline & (5.195) & (10.138) & $(-1.764)$ & (1.701) & (1.202) & \\
\hline \multirow{2}{*}{ Current Year } & $590.022 * *$ & $0.005^{* *}$ & -130.45 & $20731.13^{*}$ & -9.434 & 0.485 \\
\hline & $(4.601)$ & $(9.24)$ & $(-1.345)$ & $(3.427)$ & $(-0.057)$ & \\
\hline \multirow{2}{*}{ Following Year } & $468.558^{* *}$ & $0.005^{* *}$ & -41.122 & $25372.76^{* *}$ & -191.272 & 0.447 \\
\hline & $(3.568)$ & $(9.117)$ & $(-0.448)$ & $(4.496)$ & $(-1.201)$ & \\
\hline \multicolumn{7}{|l|}{ Panel 2: Gartner } \\
\hline \multirow{2}{*}{ Prior Year } & $219.501 * *$ & $0.001 * *$ & -32.04 & -1924.944 & 32.968 & 0.229 \\
\hline & (6.77) & (5.754) & $(-1.224)$ & $(-1.341)$ & $(0.855)$ & \\
\hline \multirow{2}{*}{ Current Year } & $196.662 * *$ & $0.001 * *$ & -10.002 & -52.74 & -40.74 & 0.209 \\
\hline & $(6.175)$ & $(5.783)$ & $(-0.415)$ & $(-0.035)$ & $(-0.997)$ & \\
\hline \multirow{2}{*}{ Following Year } & $174.717 * *$ & $0.001 * *$ & 0.945 & 1424.408 & 3.146 & 0.19 \\
\hline & $(5.489)$ & $(5.423)$ & $(0.043)$ & $(1.041)$ & $(0.082)$ & \\
\hline \multicolumn{7}{|l|}{ Panel 3: Score } \\
\hline \multirow{2}{*}{ Prior Year } & $2.629 * *$ & $8.02 \mathrm{E}-06 * *$ & 0.222 & $42.741 * *$ & -0.101 & 0.504 \\
\hline & (11.00) & $(9.62)$ & $(1.153)$ & (4.04) & $(-0.355)$ & \\
\hline \multirow{2}{*}{ Current Year } & $2.471 * *$ & $8.60 \mathrm{E}-06^{* *}$ & 0.267 & $56.477 * *$ & -0.053 & 0.51 \\
\hline & $(10.722)$ & $(9.427)$ & $(1.533)$ & $(5.194)$ & $(-0.181)$ & \\
\hline \multirow{2}{*}{ Following Year } & $2.335^{* *}$ & $9.47 \mathrm{E}-06^{* *}$ & 0.289 & $70.631 * *$ & -0.271 & 0.515 \\
\hline & (10.309) & $(9.432)$ & (1.829) & (7.255) & $(-0.986)$ & \\
\hline
\end{tabular}

Note: (1) ${ }^{* *}$ : Correlation is significant at the 0.01 level (2-tailed); (2) *: Correlation is significant at the 0.05 level (2-tailed)

five quality dimensions of SCM excellence. Overall, the correlation analysis shows moderate to low interrelations among these quality dimensions. However, a relatively higher correlation (0.634) is found between two subjective voting measures, Peer Evaluation and Gartner Opinion. It indicates that industrial peer experts may share similar judgement with Gartner's consultant. In addition, two voting measures demonstrate a moderately negative correlation $(-0.315$ and -0.325$)$ with 3 -Year ROA, which implies low association between voting measures and financial returns. On the other hand, the composite score is highly correlated with two voting measures (0.742 and 0.704$)$, moderately correlated with Revenue Growth and Inventory Turnover (0.453 and 0.444), and lowly correlated with weighted ROA (0.062). This is consistent with the findings in McGuire, et al. (1990), which find that operating income and revenue growth have little impact on the evaluation of firm reputation.

The second panel uses the current year values of several selected market variables to examine their bivariant relationships with the Gartner quality dimensions. The results show that Peer Evaluation and Composite Score are highly associated with Market Value (0.656 and 0.647), so as between System Risk and Beta (0.726). Composite Score is also moderately associated with Alpha (0.409), indicating that abnormal stock return may contribute to improve a firm's SCM reputation, or verse visa.

The panel 3 and 4 are constructed in the same way as the panel 2, but with firm data from the prior year and the following year, respectively. The purpose of these two panels is to investigate the differences in correlations between various test periods. More specifically, we find that current year's Peer Evaluation is 
more related to last year's Market Value than the next year (0.702 vs. 0.607$)$. It means that peer evaluators are largely influenced by prior financial performance but have lower capability to predict future performance. This retrospective pattern is also found between Peer Evaluation and Stock Return (0.176 vs. 0.034) and Composite Score and Market Value (0.667 vs. 0.565$)$. The only exception is between Inventory and Alpha, where inventory is more associated with the next year's alpha value than the prior year's value. Although it is not the focus of the present study, our results again confirm the contributions of inventory management to financial outcomes, which is consistent with the findings in the literature (Chen et al., 2005).

In the first regression study, Peer Evaluation is regressed on firms' Market Value, Beta, Alpha, and Market Return, using prior, current, and following year data, respectively. The purpose of this regression study is to examine the impacts of several selected market variables on peer evaluations in different time periods. Three interesting results are found from the Panel 1. First, the influence of a firm's market value on peer evaluation is statistically significant and is quite constant across different test periods. As the market value is approximated as media focus in this study, we find that the peer evaluation is likely to be influenced by a firm's media exposure all the times, as suggested by our second research hypothesis. Although temporary effects may occur due to annual release of the Gartner list (Shi \& Yu, 2018), long-term effects are stable over the three-year test period. Second, both Beta and Market Return are not statistically significant in the first regression model. It means that the peer experts do not pay much attention to detailed market information, such as volatility and stock returns, when they vote for SCM excellence. This finding is reasonable because the SCM experts are not trained as a financial professional and are somewhat isolated from day-to-day financial market information. Third, the Alpha value, which represents abnormal returns in financial markets, gives mixing results on its relationship with peer evaluation. The regression results show that SCM experts tend to ignore previous stock performance since the coefficient of Alpha is not statistically significant in the prior year. However, it is worth noting that the coefficient of Alpha not only becomes statistically significant during the current and following year, but also imposes larger impacts on peer evaluation than in the prior year. Last but not least, we find that the adjusted $\mathrm{R}^{2}$ decreases during the three-year test period $(0.523,0.485$, and 0.447 for the prior year, the current year, and the following year, respectively). Considering Market Value is the only significant variable in the regression model for the prior year, we conclude that, when they evaluate SCM excellence, peer evaluators are more influenced by a firm's media exposure than market performance in the prior year.

Then we regress Gartner Opinion on the same set of variables as in the Panel 1 and the results are presented in the panel 2. Comparing to the first panel, a notable difference is that Market Value is the only significant variable during the three-year test period. The results show that in-house Gartner consultants are not influenced as heavily as peer experts by financial market variables. At the same time, we find that the adjusted $\mathrm{R}^{2}$ in the panel 2 is much lower than in the panel 1 (dropped from around 0.5 to around 0.2 ), which reminds us that some undiscovered variables may contribute to Gartner consultants' opinions.

The last regression in this study is to regress Composite Scores on the same set of variables. The major purpose is to investigate whether overall SCM excellence relies on prior financial performance and provides a good estimate for future market performance. Three findings are worth mentioning from the panel 3. First, the coefficients of Alpha are increasing during the 3-year test period and are all statistically significant. Its growing explanation power indicates that the composite score in the Gartner list are more capable of predicting abnormal returns in the following year than the prior year. Second, unlike the decreasing explanation power in the Peer Evaluation and Gartner Opinion (panel 1 and 2), the adjusted $\mathrm{R}^{2}$ is quite stable throughout the 3-year test period. More specifically, about half of the variations in Composite Score could be explained by the selected market variables, especially Market Value and Alpha. Third, similar to Peer Evaluation and Gartner Opinion (panel 1 and 2), Beta and Market Return are again not statistically significant. It implies that the both industrial experts and Gartner consultants do not closely follow daily financial market information, no matter which time period is tested. 


\section{CONCLUSION}

Being a widely accepted measure for SCM excellence, the Gartner lists are used as valuable data sources for various empirical studies. The Gartner lists applied rigorous processes to collect data from various sources and well balanced qualitative and quantitative methods to generate SCM excellence rankings. As the correlation study shows, the Gartner list is significantly improved from other corporate reputation indexes with moderate to low correlations among its quality dimensions. However, like all ranking systems involving subjective voting, evaluators are still likely influenced by implicit market information during their decision processes.

Therefore, this study aims to investigate whether the composite score in the Gartner list is a true reflection of a firm's SCM excellence. If not so, are there other factors influencing the decision process? By investigating the relationship between several selected market variables and the Gartner quality dimensions, this study find that the composite score is largely affected by a firm's market value and alpha value, but is not associated with the firm's beta value and market return. In other words, evaluators are likely to be impressed by a firm's media exposure and relative strength to its competitors, but are not much concerned with the firm's detailed market information, such as risk level and absolute return. In addition, the composite score in the Gartner list seems to be influenced by a firm's prior market information, but lacks the ability to predict its future market performance.

Two research directions are worth mentioning for further exploration in his area. First, this study has noted the behavioral difference between industrial experts and Gartner consultants. The regression analysis shows that the explanation power of the selected market variables is much lower to Gartner opinion than to Peer Evaluation. Therefore, additional attributing factors applied to Gartner Opinion need to be further studied. Second, this study does not include the Gartner list data after 2016, due to the new addition of CSR score to the Gartner survey from that year. Since larger dataset is preferred in statistical analysis, a novel method is called to incorporate the newest Gartner data into empirical studies. 


\section{REFERENCES}

Altman, E. (1968). Financial ratios, discriminant analysis and the prediction of corporate Bankruptcy. The Journal of Finance, 23(4), 589-609. doi:10.1111/j.1540-6261.1968.tb00843.x

Brown, B., \& Perry, S. (1994). Removing the financial performance halo from Fortune's "most admired" companies. Academy of Management Journal, 37(5), 1347-1359.

Chen, H., Frank, M. Z., \& Wu, O. Q. (2005). What actually happened to the inventories of American companies between 1981 and 2000? Management Science, 51(7), 1015-1031. doi:10.1287/mnsc.1050.0368

Chen, I. J., Paulraj, A., \& Lado, A. A. (2004). Strategic purchasing, supply management, and firm performance. Journal of Operations Management, 22(5), 505-523. doi:10.1016/j.jom.2004.06.002

Christoper, M., \& Ryals, L. (1999). Supply chain strategy: Its impact on shareholder value. International Journal of Logistics Management, 10(1), 1-10. doi:10.1108/09574099910805897

Eberl, M., \& Schwaiger, M. (2005). Corporate reputation: Disentangling the effects on financial performance. European Journal of Marketing, 39(7/8), 838-854. doi:10.1108/03090560510601798

Ellinger, A., Natarajarathinam, M., Adams, F. G., Gray, J. B., Hofman, D., \& O'Marah, K. (2011). Supply chain management competency and firm financial success. Journal of Business Logistics, 32(3), 214-226. doi:10.1111/j.2158-1592.2011.01018.x

Ellinger, A., Shin, H., Northington, W. M., Adams, F. G., Hofman, D., \& O'Marah, K. (2012). The influence of supply chain management competency on customer satisfaction and shareholder value. Supply Chain Management, 17(3), 249-262. doi:10.1108/13598541211227090

Flanagan, D., O'Shaughnessy, K. C., \& Palmer, T. B. (2011). Re-Assessing the relationship between the Fortune reputation data and financial performance: Overwhelming influence or just a part of the puzzle? Corporate Reputation Review, 14(1), 3-14. doi:10.1057/crr.2011.4

Fulmer, I. S., Gerhart, B., \& Scott, K. S. (2003). Are the 100 best better? An empirical investigation of the relationship between being a 'great place to work' and firm performance. Personnel Psychology, 56(4), 965-993. doi:10.1111/j.1744-6570.2003.tb00246.x

Hendricks, K. B., \& Singhal, V. R. (2003). The effect of supply chain glitches on shareholder wealth. Journal of Operations Management, 21(5), 501-522. doi:10.1016/j.jom.2003.02.003

Hendricks, K. B., \& Singhal, V. R. (2005). An empirical analysis of the effect of supply chain disruptions on long-run stock price performance and risk of the firm. Production and Operations Management, 14(1), 35-52. doi:10.1111/j.1937-5956.2005.tb00008.x

Hendricks, K. B., \& Singhal, V. R. (2008). The effect of product introduction delays on operating performance. Management Science, 54(5), 878-892. doi:10.1287/mnsc.1070.0805

Hendricks, K. B., \& Singhal, V. R. (2009). Demand-supply mismatch and stock market reaction: Evidence from excess inventory announcements. Manufacturing \& Service Operations Management: $M$ \& SOM, 11(3), 509-524. doi:10.1287/msom.1080.0237

Hendricks, K. B., \& Singhal, V. R. (2014). The Effect of Demand-Supply Mismatches on Firm Risk. Production and Operations Management, 23(12), 2137-2151. doi:10.1111/poms.12084

Inglis, R., Morley, C., \& Sammut, P. (2006). Corporate reputation and organizational performance: An Australian study. Managerial Auditing Journal, 21(9), 934-947. doi:10.1108/02686900610705028

Johnson, M., \& Templar, S. (2011). The relationships between supply chain and firm performance: The development and testing of a unified proxy. International Journal of Physical Distribution \& Logistics Management, 41(2), 88-103. doi:10.1108/09600031111118512

McGuire, J. B., Schneeweis, T., \& Branch, B. (1990). Perceptions of firm quality: A cause or result of firm performance. Journal of Management, 16(1), 167-180. doi:10.1177/014920639001600112

Roberts, P., \& Dowling, G. (2002). Corporate reputation and sustained superior financial performance. Strategic Management Journal, 23(12), 1077-1093. doi:10.1002/smj.274 
Rose, C., \& Thomsen, S. (2004). The impact of corporate reputation on performance: Some Danish evidence. European Management Journal, 22(2), 201-210. doi:10.1016/j.emj.2004.01.012

Shi, M., \& Yu, W. (2013). Supply chain management and financial performance: Literature review and future directions. International Journal of Operations \& Production Management, 33(10), 1283-1317. doi:10.1108/ IJOPM-03-2012-0112

Shi, M., \& Yu, W. (2018). Market reactions to supply chain excellence. California State University, Los Angeles.

Swink, M. L., Golecha, R., \& Richardson, T. (2010). Does supply chain excellence really pay off? Supply Chain Management Review, 14(2), 14-21.

Min Shi currently is an associate professor in the Department of Management at California State University, Los Angeles, and serves as the director of Center for Logistics and Supply Chain Management. Before joining Cal State LA, Dr. Shi hold various positions at Cal Poly Pomona, Marist College, and Rutgers University. Dr. Shi's research and teaching interests include operations management, supply chain management, and operations/ finance interface. He has published several research papers in leading refereed journals, such as Journal of the Operational Research Society, International Journal of Operations \& Production Management, Applied Psychological Measurement, and International Journal of Operations Research and Information Systems. Dr. Shi received his PhD degree in Management from Rutgers, the State University of New Jersey. 